\title{
Germination characteristics among different sheepgrass (Leymus chinensis) germplasms during the seed development and after-ripening stages
}

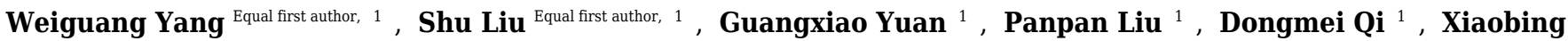 \\ Dong ${ }^{1}$, Hui Liu ${ }^{1}$, Gongshe Liu ${ }^{\text {Corresp.. }}{ }^{1}$, Xiaoxia Li ${ }^{\text {Corresp. } 1}$ \\ ${ }^{1}$ Chinese Academy of Sciences, Institute of Botany, BEIJING, China \\ Corresponding Authors: Gongshe Liu, Xiaoxia Li \\ Email address: liugs@ibcas.ac.cn, lixx2013@ibcas.ac.cn
}

Sheepgrass (Leymus chinensis (Trin.) Tzvel) is an important forage grass in the Eurasian steppe. However, little information is available concerning its seed morphological features and germination characteristics during seed development and after-ripening among different germplasms. To clarify the appropriate seed harvest time and the effects of germplasm, seed development and after-ripening on seed germination, 20 germplasms of sheepgrass were selected. Moreover, the seed morphological and physical changes as well as the seed germination and dormancy characteristics of sheepgrass during see $d$ development stages were analyzed using a 7 - $d$ gradient of day after pollination (DAP). The results indicated that the seed water content decreased significantly during $35-42$ DAP and that the highest seed germination rate of most germplasms was observed at 35 42 DAP. Thus, 35 - 42 DAP will be the best time to harvest sheepgrass to obtain the maximum seed germination rate and avoid seed shattering. Furthermore, our results indicated that there were 6 types of germination patterns, including germplasms with increasing germination rates in the developing seed, such as S19 and S13, and germplasms that maintained a consistently low germination rate, such as S10. Moreover, we compared the seed germination rate of 8 germplasms during seed development in both 2016 and 2017, and the results indicated that the seed germination patterns of the 8 germplasms were highly consistent between the two consecutive years, suggesting that germplasm rather than year is the major factor in determining germination during seed development. The effect of after-ripening on seed germination was different among the germplasms, where 4 types of germination patterns were revealed for 10 germplasms and resulted in various dormancy features. A two-factor ANOVA analysis suggested that the germplasm of the sheepgrass has a large influence on seed germination, whether during seed development or after-ripening. Thus, these findings lay the foundation for future studies on seed dormancy and germination and may guide the breeding of new cultivars of 
sheepgrass with better germination performance. 
1 Germination characteristics among different sheepgrass

2 (Leymus chinensis) germplasms during the seed development

3 and after-ripening stages

Weiguang Yang1, 2, 3\#, Shu Liu', 2\#, Guangxiao Yuan ${ }^{1,2}$, Panpan Liu', ${ }^{1,}$, Dongmei Qi',

1. Institute of Botany, Chinese Academy of Sciences, Beijing 100093, China;

2. University of Chinese Academy of Sciences, Beijing 100049, China;

3. Institute of Animal Sciences in Heilongjiang province, Qiqihar 161005, China.

* Corresponding author

GL: (Tel: +86-10-62836227; fax: +86-10-62836227; email: liugs@ibcas.ac.cn) and XL: (Tel:

+86-10-62836242; fax: +86-10-62836227; email: lixx2013@ibcas.ac.cn)

\# These authors contributed equally to this work.

Abstract: Sheepgrass (Leymus chinensis (Trin.) Tzvel) is an important forage grass in the Eurasian steppe. However, little information is available concerning its seed morphological features and germination characteristics during seed development and after-ripening among different germplasms. To clarify the appropriate seed harvest time and the effects of germplasm, seed development and after-ripening on seed germination, 20 germplasms of sheepgrass were selected. Moreover, the seed morphological and physical changes as well as the seed germination and dormancy characteristics of sheepgrass during seed development stages were analyzed using a 7 - $d$ gradient of day after pollination (DAP). The results indicated that the seed water content decreased significantly during 35 - 42 DAP and that the highest seed germination rate of most germplasms was observed at 35 - 42 DAP. Thus, 35 - 42 DAP will be the best time to harvest sheepgrass to obtain the maximum seed germination rate and avoid seed shattering. Furthermore, our results indicated that there were 6 types of germination patterns, including germplasms with increasing germination rates in the developing seed, such as S19 and S13, and germplasms that maintained a consistently low germination rate, such as S10. Moreover, we compared the seed germination rate of 8 germplasms during seed development in both 2016 and 2017, and the results indicated that the seed germination patterns of the 8 germplasms were highly consistent between the two consecutive years, suggesting that germplasm rather than year is the major factor in determining germination during seed development. The effect of after-ripening on seed germination was different among the germplasms, where 4 types of germination patterns were revealed for 10 germplasms and resulted in various dormancy features. A two-factor ANOVA 
analysis suggested that the germplasm of the sheepgrass has a large influence on seed germination, whether during seed development or after-ripening. Thus, these findings lay the foundation for future studies on seed dormancy and germination and may guide the breeding of new cultivars of sheepgrass with better germination performance.

\section{Introduction}

Sheepgrass (Leymus chinensis (Trin.) Tzvel) is a perennial species of Poaceae that is widely distributed in the eastern part of the Eurasian steppe, the northern and eastern parts of the People's Republic of Mongolia, and the northern and northeastern grasslands of China (Lin et al. 2011). As the dominant species in the region and one of the most promising forage grasses, sheepgrass is well known for its abundant foliage, high palatability and high tolerance to various environmental stresses, including arid, saline and alkaline soils (Lin et al. 2011; Liu \& QI 2004; $\mathrm{Xu} \&$ Zhou 2005). Therefore, sheepgrass is considered to be valuable in both animal husbandry and grassland restoration, and there has been a great demand for high quality sheepgrass seeds in recent decades (Liu \& Li 2015). However, seed germination of sheepgrass is relatively low and unstable due to strong seed dormancy, which limits seed utilization and initial grassland establishment.

Previous studies on the seed dormancy and germination of sheepgrass have mostly focused on dormancy breaking methods and the environmental and hormonal effects on germination (He et al. 2016; Zhang et al. 2006). The mechanical restriction of the lemma is considered to be the major cause of sheepgrass seed dormancy because removing the lemma can significantly increase germination (Ma et al. 2008). Furthermore, it was reported that the seed dormancy of sheepgrass was significantly affected by the lemma, palea, pericarp/testa and endosperm of the seed, and their average contribution to seed dormancy was $23.4 \%, 6.2 \%, 28.4 \%$ and $42.0 \%$, respectively (He et al. 2016). However, the ecological and physiological role of the lemma was revealed; it plays important roles in water uptake, dehydration and salt tolerance during germination (Lin et al. 2016a). In studies, the dormancy breaking methods for sheepgrass seed have varied from low temperature treatments to chemical agents, including PEG and GA3 (Gu et al. 2005; Liu et al. 2002; Zhang et al. 2006). Multiple methods to break seed dormancy have been developed; for instance, a combination of seed soaking treatments, which was to presoak the seed in distilled water for 1 day and then soak it in $30 \% \mathrm{NaOH}$ for $1 \mathrm{~h}$, followed by treatment with $300 \mu \mathrm{M} \mathrm{GA}_{3}$,was recently reported as an optimum dormancy-breaking method (He et al. 2016). Temperature and plant hormones are considered crucial factors in the regulation of the germination of sheepgrass. Plant hormones, including GA and ABA, are involved in seed dormancy and seed germination in many studies (Brady \& McCourt 2003; Kermode 2005). 
Previous studies have shown that conditions with fluctuating temperatures are optimal for germination and dormancy-breaking in sheepgrass, as several studies have reported that the germination rate of sheepgrass could be maximized with temperature sets of $20 / 30^{\circ} \mathrm{C}$ ( $\mathrm{Hu}$ et al. 2012 ) or $16 / 28^{\circ} \mathrm{C}$ (Yang et al. 2018). It has also been indicated that a change in temperature affects germination by contributing to GA biosynthesis during seed imbibition (Hu et al. 2012). However, previous studies on the dormancy and germination of sheepgrass seeds mainly aimed to study the mature seeds of very few germplasms, and the germination characteristics during seed development and after-ripening are still unclear.

Seed development begins with a double fertilization process, after which the egg cell develops into the embryo and the polar nuclei develop into the endosperm (Goldberg et al. 1994). In monocots such as rye grass and cereal crops that are covered by the lemma, the caryopsis consists of the embryo, endosperm, and pericarp, where endosperm occupies the most space in the mature seed (James et al. 2003). During the seed development of rice, it was reported that embryogenesis is completed at approximately 6 DAF (days after fertilization) and that the seed filling process occurs at $6 \mathrm{DAF}$ until $20 \mathrm{DAF}$ (Xu et al. 2008). In wheat, which spends relatively more time in the seed developing stage, the seed filling process begins at approximately $8 \mathrm{DAF}$ and lasts until 28 DAF (Leprince et al. 2017; Nasehzadeh \& Ellis 2017). Since each part of the developing seed structure contributes to seed dormancy in sheepgrass, embryogenesis and endosperm development and the afterwards late maturation could critically determine the seed germination characteristics (Bewley \& Black 1994; Hu et al. 2012).

After the last phase of seed development and maturation, harvesting seed at the proper stage of maturity is of practical importance in seed production (Finch-Savage \& Bassel 2016). Early harvesting may lead to low seed vigor and poor establishment because of an insufficient level of maturation, while delaying harvest can cause seed loss under unfavorable environmental conditions (Leprince et al. 2017). It was recently reported that the optimum harvest time for sheepgrass seed is approximately 39 days after peak anthesis at which time the maximum seed quality, including seed weight, and the ability to germinate have been acquired (Lin et al. 2016a). However, the flowering time of sheepgrass lacks uniformity, varying among cultivars and even batches, which may considerably affect practical seed harvesting. In addition, exposing harvested seed to warm and dry conditions may result in a progressive loss of dormancy, which is commonly known as seed after-ripening, and the change in seed vigor after harvest remains largely undetermined (Baskin \& Baskin 2014; Foley 2008). Studies on the effect of afterripening on promoting seed germination had have been conducted in several species, including rice (Veasey et al. 2004), Stipa (Zhang et al. 2017) and Physaria (Cruz et al. 2012), indicating that the speed and extent of after-ripening can vary among species as well as different cultivars (Baskin \& Baskin 2014; Veasey et al. 2004). After-ripening of the mature seed is practically 
107 significant for plantation and seed production, but little has been revealed on the after-ripening 108 effect on harvested seeds of sheepgrass.

109 Variations in seed dormancy exist in crop germplasms as an adaptation strategy to regulate

110

111

112 germination timing ( $\mathrm{Gu}$ et al. 2003). The traits related to dormancy are considered to be associated with multiple quantitative trait loci (QTL) in barley, wheat and rice (Gu et al. 2015). Furthermore, study in hybrid wildryes (Leymus) indicated the pleiotropic QTL on Leymus LG6a with major effects on both seed shattering and seed dormancy (Larson \& Kellogg, 2009). However, the variations in seed dormancy and germination among cultivars of sheepgrass remain largely unknown (Zhao et al. 2018). In recent years, several new varieties of sheepgrass, for instance the "Zhongke" series, have been identified as good candidates for sheepgrass production (Liu \& Li 2015). Considering the potential value of multiple varieties, newly cultivated and conserved germplasms require further evaluation, which may lead to a comprehensive understanding of the seed dormancy and germination characteristics of sheepgrass. Therefore, based on substantial cultivars of conserved or previously bred sheepgrass, we aimed to (i) investigate the morphological and physiological characteristics of sheepgrass during seed development and (ii) evaluate the variations in seed dormancy and germination among different germplasms of sheepgrass during seed development as well as the after-ripening process in this study.

\section{Materials and methods}

\section{Seed collection}

All the involved germplasms of sheepgrass were conserved in the Laboratory of Genetic Resources of the Sheepgrass Research Group at Institute of Botany, Chinese Academy of Sciences, Beijing, China. Twenty germplasms of sheepgrass, coded as K8, C5, C1, Z37, C54, S17, S10, S2, C19, S16, Q6, N4, N14, C18, S3, N2, N15, K4, S13 and S19, were selected for the investigation on seed germination during seed development and seed after-ripening. All seeds were harvested under strict hybridization conditions within each germplasm in both 2016 and 2017.

\section{Morphological and physical observations of the developing seed}

During seed development after flowering, a total of more than 100 spikelets from different plants of K4, S19, S10 and N14 were collected, dissected and photographed using a digital camera (Nikon EOS 6D) at different days after pollination (DAP). In addition, the average fresh weight and dry weight of the seeds of K4, S19, S10 and N14 at different days after pollination (DAP) were tested at 7 DAP, 14 DAP, 21 DAP, 28 DAP, 35 DAP and 42 DAP from May to June 2016. 
142 The seed water content was calculated based on the fresh and dry weight of the seeds. Three 143 replicates of 50 seeds were performed for each germplasm.

144

\section{Germination test}

The germination type of sheepgrass is hypogeal. The germination rate during seed development was tested in twenty germplasms of sheepgrass at 7 DAP, 14 DAP, 21 DAP, 28 DAP, 35 DAP and 42 DAP. Harvested at 42 DAP, the seeds of all germplasms were stored in darkness at room temperature with a relative humidity of $30 \%$ as the after-ripening treatment. To determine the after-ripening effect, the germination rate of ten germplasms was tested at 0 days after harvest (DAH), $15 \mathrm{DAH}, 30 \mathrm{DAH}$ and $60 \mathrm{DAH}$, while the $0 \mathrm{DAH}$ treatments were harvested at $42 \mathrm{DAP}$. Three replicates of 30 seeds were used for each germplasm at stage of seed development and during after-ripening process. The seeds were selected and placed in 9 - cm Petri dishes on two layers of moistened filter paper. The dishes were placed in an incubator for 18 days under an alternating temperature controlled system of $28^{\circ} \mathrm{C}$ for $12 \mathrm{~h}$ and $16^{\circ} \mathrm{C}$ for $12 \mathrm{~h}$. The relative humidity in the incubator was maintained at $35 \%$ and light at $500 \mu \mathrm{mol} \cdot \mathrm{m}^{-2} \mathrm{~s}^{-1}$ was used during the high temperature period each day. Distilled water was added to maintain the moisture content of the Petri dishes as necessary. A seed was considered to have germinated when they emerged radical length reached at least $2 \mathrm{~mm}$ (International Seed Testing Association, 1996). The percentage germination was calculated as the percentage of the seeds that germinated within the incubation period.

\section{Data analysis}

The experimental designs are Simple Random Design, and the data were statistically analyzed using SPSS 17.0. Two-way analysis of variance (ANOVA) was performed to test the effects of germplasm and developmental stage, germplasm and year, germplasm and after-ripening time on seed germination. Duncan's test was used for multiple comparisons among the different treatments.

\section{Results}

\section{Morphological changes during seed development in sheepgrass}

To obtain the basic characteristics of sheepgrass seed development, we closely observed the morphological features of the developing seeds from flowering until maturity. The structure of a single flower of sheepgrass includes the lemma, the palea, the three stamens and the pistil (Figure 1A). During the flowering process of sheepgrass, the two flowers near the rachilla 
blossomed first, and then the other flowers opened on the spikelet. After the anthers were confided in the lemma during 5 - 7 DAP, they started to fall. The fertilized ovary began to expand at 3 - 4 DAP, and the spikelet fully expanded. Starch was deposited in the grain, and the inside of the grain was milk white around 8 DAP. As the starch accumulated, the inner content of the seed became a white emulsion and became thicker at 16 DAP. Later, as the seed continued to develop and mature, the seed coat began to gain color until the wax inside the seed turned into lumps. At approximately 20 DAP, the seed began to accumulate pigment near the embryo end, and the seed coat gradually turned dark purple or yellow, subsequently turning harder. Furthermore, the palea turned yellow at both ends and became tightly bound to the caryopsis, at which point it was difficult to entirely remove the palea from the caryopsis. Next, the spikelet began to become dehydrated and gradually turned yellow, at which time the seed was considered physiologically mature. The color of the seed coat was mainly observed as dark purple or yellow at approximately 26 DAP, while the palea basically started turning yellow or brown (Figure 1B), and a population photo of sheepgrass at seed maturity period was in the supplementary Figure 1. In addition, it was observed that the flowering time of sheepgrass varied among the germplasms, and based on the flowering time, the twenty germplasms of sheepgrass were classified into three groups: the early, the middle and the late flowering types (Table 1).

\section{Physical changes during seed development in sheepgrass}

To investigate the physiological changes during seed development of sheepgrass, we measured the reserve accumulation and water loss at the seed developmental stages of 7 DAP, 14 DAP, 21 DAP, 28 DAP, 35 DAP and 42 DAP. The results showed that the seed dry weight rapidly increased until 7 - 14 DAP. After 14 DAP, the increase in seed dry weight slowed and then the dry weight generally reached a maximum at 28 DAP. During seed development and maturation, the water content of the seed continued to decrease after 7 DAP and began to rapidly decrease after 28 DAP. The water content of the seed was reduced to under $15 \%$ at approximately 35 DAP. Afterwards, water loss from the seed continued in late maturation, and the water content fell to approximately $10 \%$ at 42 DAP (Figure 2).

\section{Effects of the developmental stages on the seed germination of different germplasms}

To further investigate the effect of germplasms on the seed germination of sheepgrass, we randomly selected 20 germplasms according to their flowering time (Table 1). During seed development, the germination rate of each germplasm was tested at 7 DAP, 14 DAP, 21 DAP, 28 DAP, 35 DAP, and 42 DAP. The results showed that the seeds of most of the germplasms were unable to germinate at $7 \mathrm{DAP}$ and that only three germplasms, C1, C5 and S17, could germinate at this time with germination rates of $1.67 \%, 5.83 \%$ and $0.83 \%$, respectively. At 14 DAP, all the 
212 germplasms excluding N15 appeared to be capable of germinating (Figure 3). The results of the 213 germination test after 14 DAP until 42 DAP showed multiple types of variation in germination 214 during seed development in different sheepgrass germplasms. We classified the germination 215 patterns of the developing seeds into the following six types: (1) the germination rate continued 216 to rise gradually with seed development, which included S13, S17, S19, N2, N15 and N14 217 (Figure 4A); (2) the germination rate continued to increase at the early developmental stages 218 until 35 DAP and then began to decrease, such as C54, Z37 and C18 (Figure 4B); (3) the 219 germination rate first decreased from 14 DAP to 21 DAP and then began to increase after 21 220 DAP, but it then appeared to fall again after 35 DAP, for example, C19 and K4 (Figure 4C); (4) a 221 zigzag pattern of changes in germination was observed for S2 and C6, in which a varying trend was observed at each of the four developmental stages (Figure 4D); (5) the germination rate first increased after 14 DAP until 21 DAP, then continued to fall until 35 DAP, and then began to increase again after 35 DAP, which only occurred for S3 (Figure 4E); and (6) the germination rate was relatively low at all of the developmental stages, including $\mathrm{C} 1, \mathrm{C} 5, \mathrm{~K} 8$ and $\mathrm{S} 10$ (Figure 4F). In addition, a two-way ANOVA was performed, and the results showed that the germination rate of the developing seed was significantly affected by both the germplasm and the developmental period $(P<0.01)$ (Table 2$)$.

\section{Effects of two consecutive years on the seed germination of different germplasms}

Considering the multiple effects on germination characteristics, the germination rates of the developing seeds of contrasting varieties of sheepgrass germplasms were consecutively recorded in two years. To determine the genetic regularities of the germination characteristics of different sheepgrass germplasms, we selected 8 germplasms and analyzed seed germination during seed development in both 2016 and 2017. The results showed that the seed germination patterns of each germplasm at the different developing stages (14, 28, and 42 DAP) were highly consistent between the two consecutive years (Figure 4). To further investigate the influence of germplasm and year on the seed germination of sheepgrass, a two-factor ANOVA was performed, which indicated that the germplasm had a significant influence on the germination characteristics of the developing seeds $(P<0.01)$ and that the seed germination rate of the developing seeds was not significantly different between the two years $(P>0.05)$ (Table 3$)$. The results showed that the germination characteristics of the developing sheepgrass seeds remained relatively constant during the two different years, suggesting that germplasm may significantly affect the seed germination rate of sheepgrass.

245 Effects of after-ripening on the seed germination of different germplasms To determine the after-ripening effect on the seed germination of sheepgrass, the seed germination rate of 10 sheepgrass germplasms were determined at 0 days, 15 days, 30 days and 
60 days after harvest. Our results showed that the germination rate of the germplasms C5, S3, and N14 tended to significantly increase during after-ripening and that the germination rate reached a peak 30 days after harvest but then dropped significantly 60 days after harvest (Figure 5A). In contrast, the germplasms S17, C18 and S19 showed a rather high germination rate when first harvested, but after 15 days of after-ripening, the germination rate was significantly reduced; however, the germination rate rose again after 30 days of after-ripening (Figure 5B). Compared to the other various patterns in the germination rate during the seed after-ripening process, germplasm Z37 showed a continuous significant increasing germination rate after harvest. Similarly, no significant decrease was observed in the seed germination rate of S10 and C19 after harvest (Figure 5C). However, the germination rate of $\mathrm{K} 4$ continued to decrease during the afterripening process (Figure 5D). Furthermore, we analyzed the effects of germplasm and afterripening time on seed germination during after-ripening, and the result of the two-factor ANOVA indicated that the variation by germplasm was greater than that by the after-ripening time (Table 4).

\section{Discussion}

For a long time, the cultivation goals for wild species have been to increase seed yield, improve fertility, make the flowering time adapt to the local climate, and reduce seed shattering and dormancy (Konishi et al. 2006). During seed development and maturation, the morphological analyses of seeds have important practical values in the evaluation of germplasms, the cultivation of new varieties, and seed quality monitoring throughout seed production (Bewley \& Black 1994). However, the seed development process of sheepgrass requires more specific morphological and physiological studies due to the limited available information. Seed shattering before harvest significantly reduces seed yield, and sheepgrass is prone to seed shattering; however, the seed does not fall off immediately when it matures (Liu et al. 2013). Furthermore, decent seed development and maturation are essential for seed vigor and longevity, despite the effects of environmental factors during seed development, such as temperature (Finch-Savage \& Bassel 2016; Sanhewe et al. 1996). Therefore, it is possible to identify the optimum harvest time through monitoring seed physiological indexes and changes in germination during different development stages. Lin et al. (Lin et al. 2016a; Lin et al. 2016b) suggested that sheepgrass seed can be harvested at 39 days after peak anthesis and 10 days after the coloration of the lemmas. In our study, the results indicated that the seed water content continued to decrease during seed development and that the water content decreased significantly during 35 - 42 DAP. At 42 DAP, the seed water content decreased to approximately 15\% (Figure 2). In addition, our study found 
that $95 \%$ of the germplasms could germinate after 14 DAP and that the highest germination rate was observed from 35 DAP to 42 DAP in most of the germplasms (Figure 3). Thus, our results suggested that the best harvest time for the different sheepgrass germplasms may be between 35 DAP and 42 DAP to ensure that the maximum germination ability of the seed has been acquired and to avoid seed shattering.

Primary dormancy is induced during the seed maturation phase and reaches a high level in freshly harvested seeds, and the level of dormancy slowly decreases during the subsequent dry storage of seeds (Graeber et al. 2012; Holdsworth et al. 2008; Larson \& Kellogg 2009). Yi et al. (Yi et al. 1997) suggested that sheepgrass undergo physiological dormancy and that the level of dormancy is the greatest in the physiological maturation period. Previous studies suggested that the ratio of abscisic acid (ABA) and gibberellin (GA) plays important roles in the regulation of seed germination and dormancy (Holdsworth et al. 2008). ABA induces seed maturation and promotes dormancy, and the seed ABA content of sheepgrass gradually increases from the milk to the ripening stage and then decreases from the ripening stage to the fully ripe period (Yi et al. 1997). GA is required for seed germination, and it can act on reactive oxygen species to release dormancy and promote seed germination (Graeber et al. 2012); in sheepgrass seed, the content of GA continuously decreases after the filling stage, reaches a minimum before the ripening stage, and then begins to increase ( $\mathrm{Hu}$ et al. 2012; Yi et al. 1997). Previous studies showed that germination varied by germplasm in wheat (Mohsen et al. 2011), rice (Bosetti et al. 2012; Gu et al. 2015) and spring barley (Briggs \& Dunn 2000), indicating the significant role of germplasm in determining seed vigor, germination and seedling growth. However, studies on the seed germination of sheepgrass were largely limited to only one or two germplasms, and the effect of germplasm on the seed germination of sheepgrass had not been identified. As multiple new sheepgrass cultivars were bred and conserved in recent decades, they have contributed to the investigations of the influence of germplasm on the variation in seed germination ( $\mathrm{Liu} \& \mathrm{Li}$ 2015). In this study, we used 20 germplasms of sheepgrass to investigate the germination characteristics during seed development, and the results showed that specific germplasms have representative germination characteristics that distinguish them from the other various sheepgrass germplasms. For example, S19 had a high germination rate, and S10 had a low germination rate (Figure 3). These sheepgrass germplasms can be introduced as perfect candidates for further studies on seed dormancy and germination in sheepgrass. In addition, the seed germination patterns of eight germplasms of sheepgrass were highly similar between two consecutive years, suggesting that germplasm has a significant influence on the seed germination of sheepgrass $(P<0.01)$ (Figure 4, Table 3).

Previous studies have suggested that the germination rate of sheepgrass seeds continuously increases during seed development and maturation (Lin et al. 2011) but was restrained by the 
318

319

320

321

322

323

324

325

326

327

328

329

330

331

332

333

334

335

336

337

338

339

340

341

\section{2}

343

344

345

346

347

348

349

350

351

germplasm of sheepgrass. Our results revealed a more comprehensive description of the changes in the germination rate of multiple germplasms during sheepgrass seed development, where 6 types of germination patterns during seed development were identified. For the different germplasms of sheepgrass, a decrease in the seed germination rate was observed during the seed development process, suggesting different variations in seed dormancy in different germplasms of sheepgrass (Figure 4). The release of seed dormancy in germplasms such as S19 was persistent during seed development, resulting in a high germination rate for the mature seeds. In contrast, the germination rate of some germplasms, such as S10, remained relatively low throughout seed development, suggesting constant strong seed dormancy. In many other germplasms, the degree of seed dormancy varied among the different developmental stages, which requires further illumination. During late seed maturation and after-ripening, seed dormancy and germination characteristics may continue to change (Carrera et al. 2008; Haimovich et al. 2008). Veasey et al. (Veasey et al. 2004) observed a variation in the loss of dormancy of different rice populations and cultivars during after-ripening, resulting in different germination patterns. In Stipa bungeana, similar variations in seed germination among cultivars during after-ripening was identified (Zhang et al. 2017). In this study, we selected 10 germplasms of sheepgrass to reveal the after-ripening effect on seed germination, and four types of after-ripening effect patterns were observed (Figure 5). Our results indicated that the afterripening effect on seed germination of sheepgrass was significantly influenced by both germplasm and storage time. We observed the effect of after-ripening on sheepgrass within two months under the general storage conditions with the main purpose to verify the variation in different germplasms; however, the effects of storage time and multiple treatments of afterripening on sheepgrass germination require further investigation.

\section{Conclusion}

This study shows that the best harvest time for different sheepgrass germplasms may be between 35 DAP and 42 DAP. Furthermore, the germination of sheepgrass seeds is significantly affected by the germplasm during both seed development and after-ripening. Hence, the germplasm of sheepgrass is the key factor determining seed germination and dormancy, and these results will lay a theoretical foundation for breeding new varieties of sheepgrass with high germination rates in the future. 


\section{Reference}

353 Baskin CC, and Baskin JM. 2014. Seeds: ecology, biogeography, and evolution of dormancy and germination San Diego: CA: Elsevier/Academic Press.

Bewley JD, and Black M. 1994. Seeds: Physiology of Development and Germination, 2nd edition. New York: Plenum Press.

Bosetti F, Montebelli C, Novembre ADLC, Chamma HP, and Pinheiro JB. 2012. Genetic variation of germination cold tolerance in Japanese rice germplasm. Breeding Science 62:209-215. 10.1270/jsbbs.62.209

Brady SM, and McCourt P. 2003. Hormone cross-talk in seed dormancy. Journal of Plant Growth Regulation 22:25-31. 10.1007/s00344-003-0018-7

Briggs KG, and Dunn GJ. 2000. Variation amongst Canadian six-row spring barley cultivars for germination and emergence characteristics in controlled environments and in the field. Canadian Journal of Plant Science 80:247-253. Doi 10.4141/P99-054

Carrera E, Holman T, Medhurst A, Dietrich D, Footitt S, Theodoulou FL, and Holdsworth MJ. 2008. Seed afterripening is a discrete developmental pathway associated with specific gene networks in Arabidopsis. Plant J 53:214-224. 10.1111/j.1365-313X.2007.03331.X

Cruz VMV, Romano G, and Dierig DA. 2012. Effects of after-ripening and storage regimens on seed-germination behavior of seven species of Physaria. Industrial Crops and Products 35:185-191. 10.1016/j.indcrop.2011.06.034

Finch-Savage WE, and Bassel GW. 2016. Seed vigour and crop establishment: extending performance beyond adaptation. Journal of Experimental Botany 67:567-591. 10.1093/jxb/erv490

Foley ME. 2008. Temperature and moisture status affect afterripening of leafy spurge (Euphorbia esula) seeds. Weed Science 56:237-243. 10.1614/Ws-07-155.1

Goldberg RB, Depaiva G, and Yadegari R. 1994. Plant Embryogenesis - Zygote to Seed. Science 266:605-614. DOI 10.1126/science.266.5185.605

Graeber K, Nakabayashi K, Miatton E, Leubner-Metzger G, and Soppe WJJ. 2012. Molecular mechanisms of seed dormancy. Plant Cell and Environment 35:1769-1786. 10.1111/j.1365-3040.2012.02542.x

$\mathrm{Gu}$ AL, Yi J, and Holubowiecz R. 2005. Effects of low temperature on seed germination of Leymus chinensis and Pascopyrum simithii. Grasslands of China 27:50-54.

Gu XY, Chen ZX, and Foley ME. 2003. Inheritance of seed dormancy in weedy rice. Crop Science 43:835-843.

Gu XY, Zhang JF, Ye H, Zhang LH, and Feng JH. 2015. Genotyping of Endosperms to Determine Seed Dormancy Genes Regulating Germination Through Embryonic, Endospermic, or Maternal Tissues in Rice. G3-Genes Genomes Genetics 5:183-193. 10.1534/g3.114.015362/-/DC1

Haimovich S, Checa MA, Mancebo G, Fuste P, and Carreras R. 2008. Treatment of endometrial hyperplasia without atypia in peri- and postmenopausal women with a levonorgestrel intrauterine device. Menopause 15:10021004. 10.1097/gme.0b013e3181659837

He XQ, Wang YR, Hu XW, Baskin CC, Baskin JM, and Lv YY. 2016. Seed dormancy and dormancy-breaking methods in Leymus chinensis (Trin.) Tzvel. (Poaceae). Grass and Forage Science 71:641-648. 10.1111/gfs. 12220

Holdsworth MJ, Bentsink L, and Soppe WJJ. 2008. Molecular networks regulating Arabidopsis seed maturation, after-ripening, dormancy and germination. New Phytologist 179:33-54. 10.1111/j.1469-8137.2008.02437.x

Hu XW, Huang XH, and Wang YR. 2012. Hormonal and temperature regulation of seed dormancy and germination 
in Leymus chinensis. Plant Growth Regulation 67:199-207. 10.1007/s10725-012-9677-3

International Seed Testing Association. 1996. Seed Sci. Technol. 24 Suppl.

James MG, Denyer K, and Myers AM. 2003. Starch synthesis in the cereal endosperm. Current Opinion in Plant Biology 6:215-222. 10.1016/S1369-5266(03)00042-6

Kermode AR. 2005. Role of abscisic acid in seed dormancy. Journal of Plant Growth Regulation 24:319-344. 10.1007/s00344-005-0110-2

Konishi S, Izawa T, Lin SY, Ebana K, Fukuta Y, Sasaki T, and Yano M. 2006. An SNP caused loss of seed shattering during rice domestication. Science 312:1392-1396. 10.1126/science.1126410

Larson SR, and Kellogg EA. 2009. Genetic Dissection of Seed Production Traits and Identification of a MajorEffect Seed Retention QTL in Hybrid Leymus (Triticeae) Wildryes. Crop Science 49:29-40. 10.2135/cropsci2008.05.0277

Leprince O, Pellizzaro A, Berriri S, and Buitink J. 2017. Late seed maturation: drying without dying. Journal of Experimental Botany 68:827-841. 10.1093/jxb/erw363

Lin J, Shao S, Zhang N, Wang Y, and Mu C. 2016a. Lemmas induce dormancy but help the seed of Leymus chinensis to resist drought and salinity conditions in Northeast China. PeerJ 4:e1485. 10.7717/peerj.1485

Lin J, Wang J, Li X, Zhang Y, Xu Q, and Mu C. 2011. Effects of saline and alkaline stresses in varying temperature regimes on seed germination of Leymus chinensis from the Songnen Grassland of China. Grass and Forage Science 66:578-584. 10.1111/j.1365-2494.2011.00818.x

Lin J, Wang Y, Qi M, Li X, Yang C, and Mu C. 2016b. Optimum harvest maturity for Leymus chinensis seed. Biol Open 5:720-725. 10.1242/bio.017780

Liu GS, and Li XX. 2015. Study on Germplasm of Leymus chinensis. Beijing, Science Press.

Liu GS, and QI DM. 2004. Research progress on the biology of Leymus chinensis. Acta Prataculturae Sinica 13:611.

Liu J, Wang EH, and Li XF. 2002. Effect of PEG on germination and active oxygen metabolism in wildrye (Leymus chinensis (Trin.) Tzvel. Or Aneurolepidium chinensis(Trin)Kitag.). Acta Prataculturae Sinica seeds 1:5964.

Liu ZJ, Chen Y, and Meng J. 2013. Seed Shattering and Relevant Traits of Leymus chinensis. Acta Agrestia Sinica 21:152-158.

Ma HY, Liang ZW, Wang ZC, Chen Y, Huang LH, and Yang F. 2008. Lemmas and endosperms significantly inhibited germination of Leymus chinensis (Trin.) Tzvel. (Poaceae). Journal of Arid Environments 72:573578. 10.1016/j.jaridenv.2007.06.013

Mohsen MN, Mahdi B, and Abolfazl T. 2011. Effect of seed size and genotype on germination characteristic and seed nutrient content of wheat. Scientific Research and Essays 6:2019-2025. 10.5897/sre11.621

Nasehzadeh M, and Ellis RH. 2017. Wheat seed weight and quality differ temporally in sensitivity to warm or cool conditions during seed development and maturation. Annals of Botany 120:479-493. 10.1093/aob/mcx074

Sanhewe AJ, Ellis RH, Hong TD, Wheeler TR, Batts GR, Hadley P, and Morison JIL. 1996. The effect of temperature and $\mathrm{CO} 2$ on seed quality development in wheat (Triticum aestivum L). Journal of Experimental Botany 47:631-637. Doi 10.1093/Jxb/47.5.631

Veasey EA, Karasawa MG, Santos PP, Rosa MS, Manani RE, and Oliveira GCX. 2004. Variation in the loss of seed dormancy during after-ripening of wild and cultivated rice species. Annals of Botany 94:875-882. Doi 10.1093/Aob/Mch215 
434

435

436

437

438

439

440

441

442

443

444

445

446

447

448

449

450

451

452
Xu SB, Li T, Deng ZY, Chong K, Xue YB, and Wang T. 2008. Dynamic proteomic analysis reveals a switch between central carbon metabolism and alcoholic fermentation in rice filling grains. Plant Physiology 148:908-925. 10.1104/pp.108.125633

Xu ZZ, and Zhou GS. 2005. Effects of water stress and nocturnal temperature on carbon allocation in the perennial grass, Leymus chinensis. Physiologia Plantarum 123:272-280.

Yang WG, Liu PP, and Yuan GX. 2018. Effects of germplasm and changing temperature on seed germination of Leymus chinensis. Acta Prataculturae Sinica. Acta Prataculturae Sinica 27:103-111.

Yi J, Li QF, and Tian RH. 1997. Seed dormancy and hormone control of germination in Leymus Hochst. Acta Agrestial Sinica 5:93-99.

Zhang R, Baskin JM, Baskin CC, Mo Q, Chen LJ, Hu XW, and Wang YR. 2017. Effect of population, collection year, after-ripening and incubation condition on seed germination of Stipa bungeana. Scientific Reports 7. Artn 13893 10.1038/S41598-017-14267-2

Zhang WD, Bi JJ, Ning TY, Liu XL, and He MR. 2006. Effects of temperature, light and other treatments on seed germination of Leymus chinensis. Canadian Journal of Plant Science 86:143-148. Doi 10.4141/P04-125

Zhao P, Li X, Jia J, Yuan G, Chen S, Qi D, Cheng L, and Liu G. 2018. LcbHLH92 from sheepgrass acts as a negative regulator of anthocyanin/proanthocyandin accumulation and influences seed dormancy. Journal of Experimental Botany 70(1):269-284. 10.1093/jxb/ery335 


\section{Figure 1}

Morphology and development of sheepgrass seeds

(A) The blooming flower of sheepgrass: An intact flower includes the lemma, the palea, the three stamens and the pistil. (B) The morphology of the developing sheepgrass seed after flowering until seed maturation: The fertilized ovary began to expand at approximately 4 DAP. As the reserves started to accumulate at 8 DAP, the seed reached the milk-ripe stage. At $16 \mathrm{DAP}$, the seed coat began to gain color, and at approximately $20 \mathrm{DAP}$, the seed coat began to gradually turn yellow or dark purple and subsequently hardened. The seed coat became fully colored at 26 DAP.
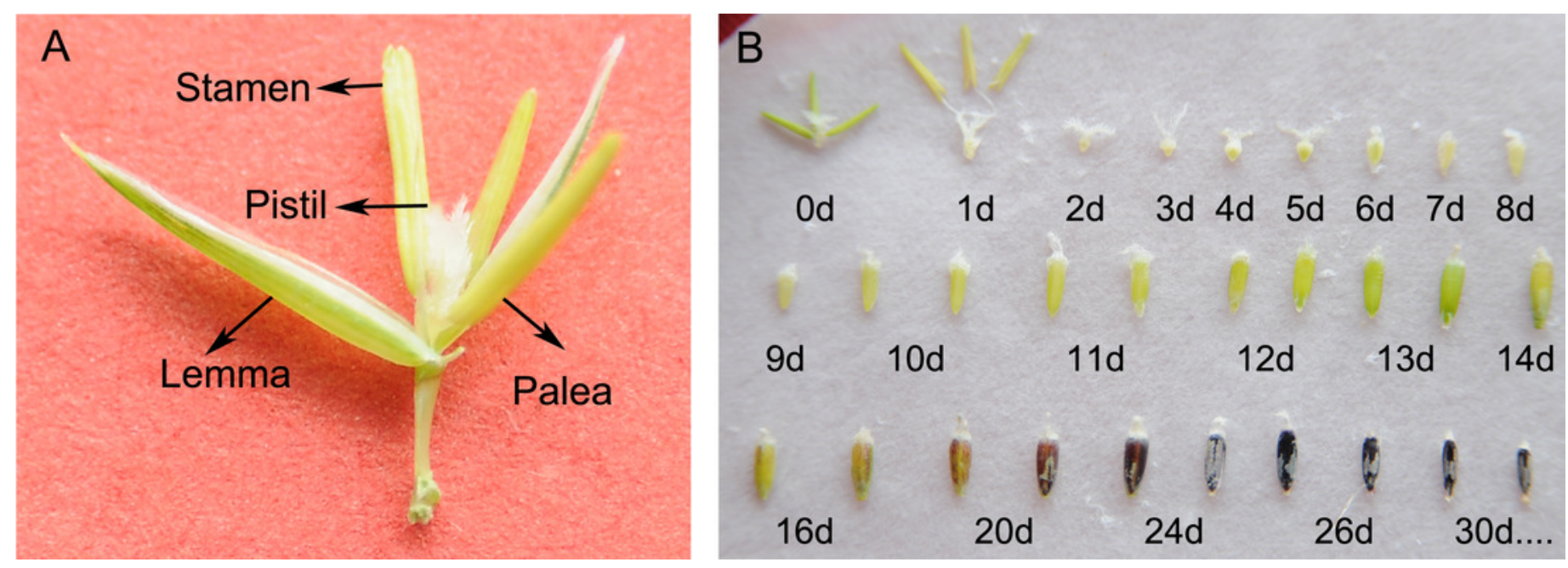
Figure 2

Change in the weight and water content of the developing seeds of sheepgrass

The results showed that the accumulation of reserves occurred mainly before14 DAP and that the seed water content decreased rapidly after 28 DAP. Bars represent the mean \pm S.E. $(n=$ $4)$.

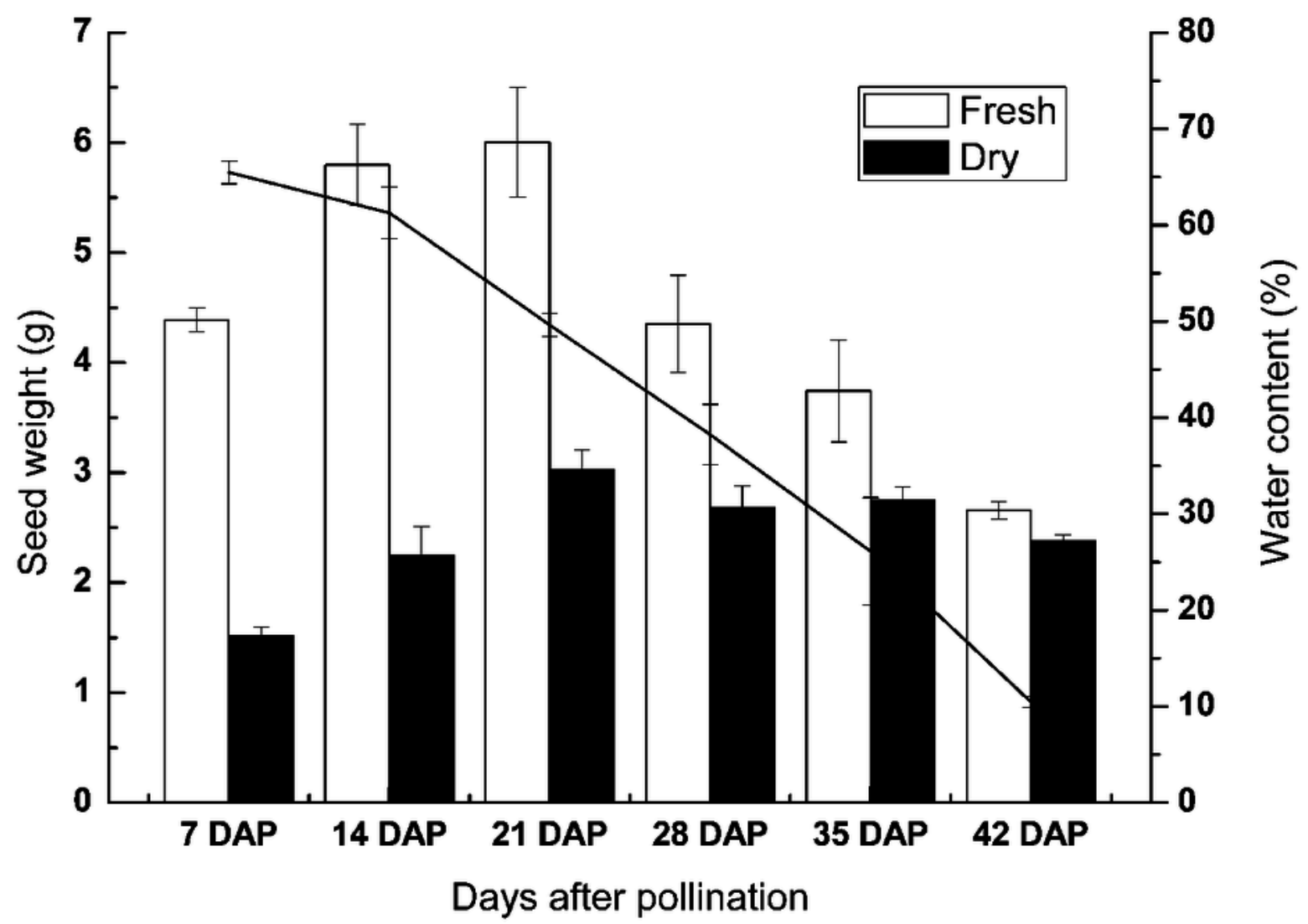




\section{Figure 3}

Six types of germination patterns during seed development of different sheepgrass germplasm

(A) Continuously increasing the germination rate during development, which included the germplasms S13, S17, S19, N2, N15 and N14. (B) Continuously increasing germination until 35 DAP and afterwards decreasing, this included the germplasms C54, Z37 and C18. (C) Increasing from 21 DAP to 35 DAP, which included the germplasms C19 and K4. (D) Increasing from 14 DAP to 21 DAP and from 28 DAP to 35 DAP, which included the germplasms S2 and Q6. (E) Increasing from 14 DAP to 21 DAP and from 35 Dap to 42 DAP, which included the germplasm S3. (F) Maintained a low germination rate during development, which included the germplasms $\mathrm{C} 1, \mathrm{C} 5, \mathrm{~K} 8$ and $\mathrm{S} 10$. Bars represent the mean \pm S.E. $(n=4)$. 

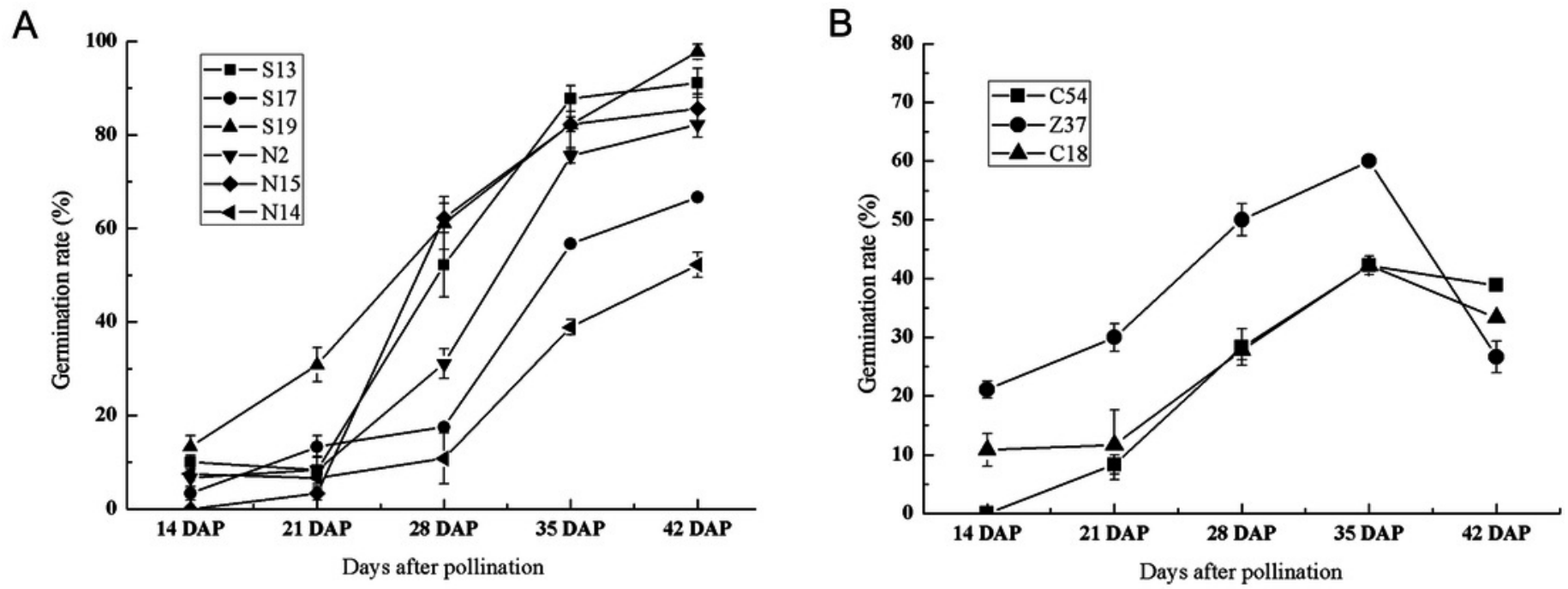

C

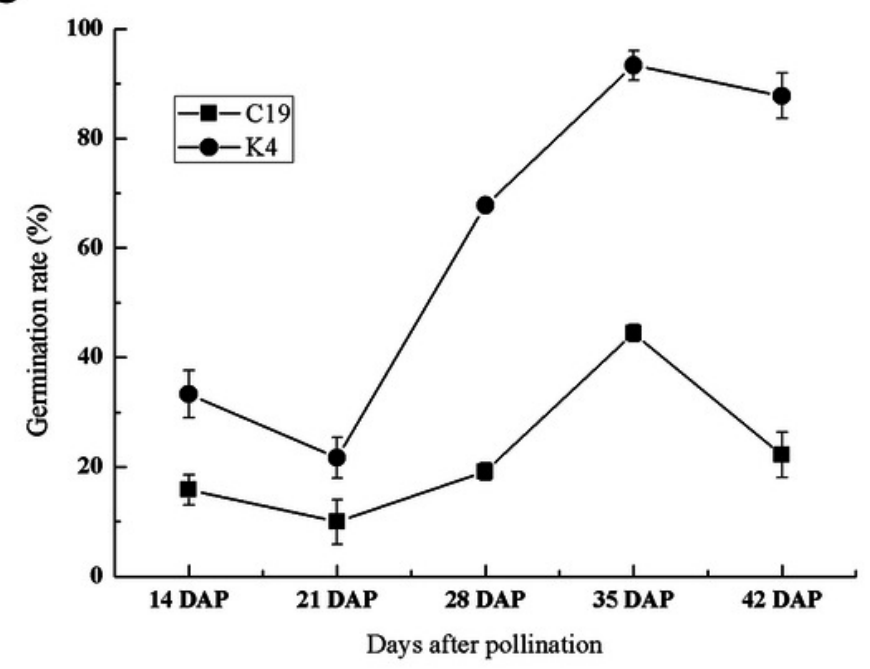

D

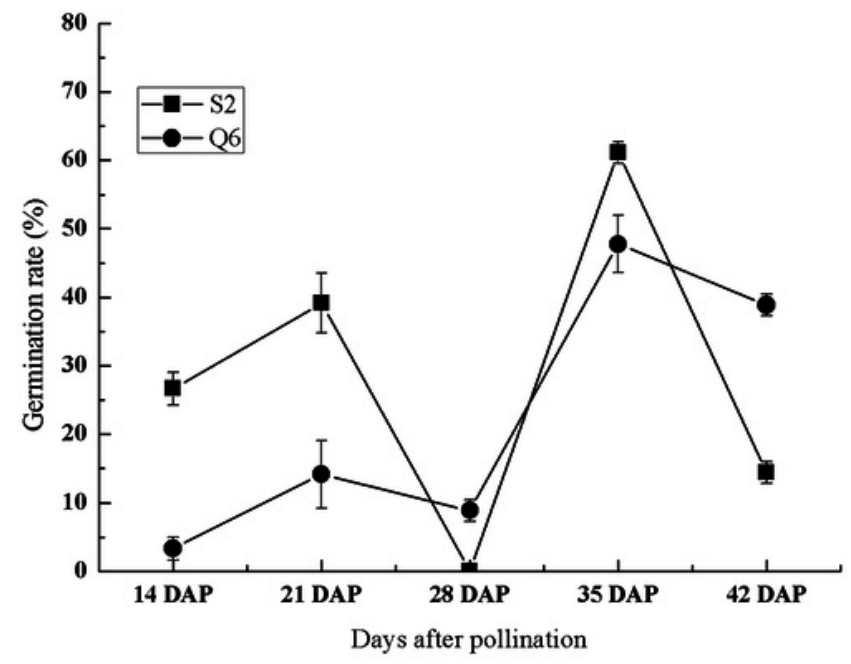

E

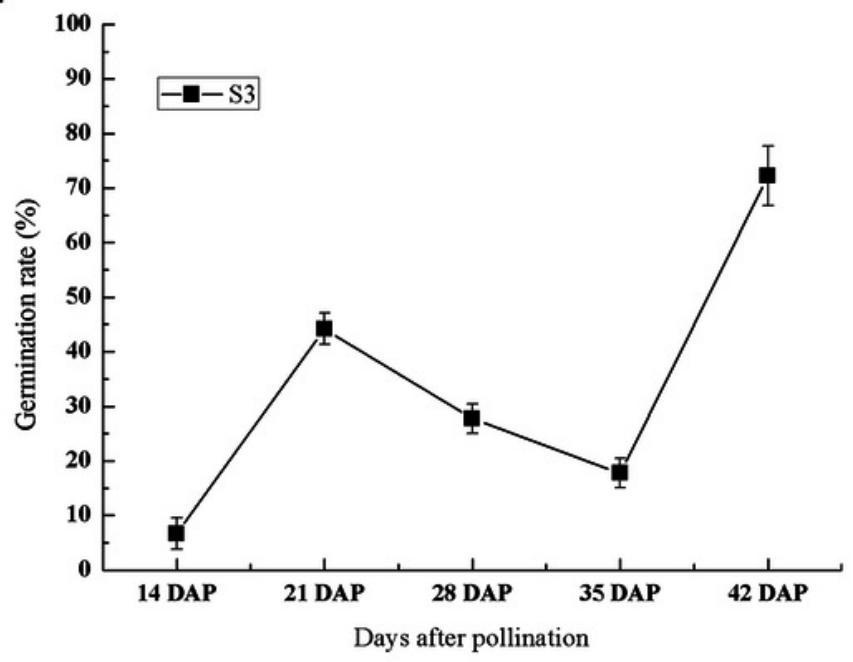

F

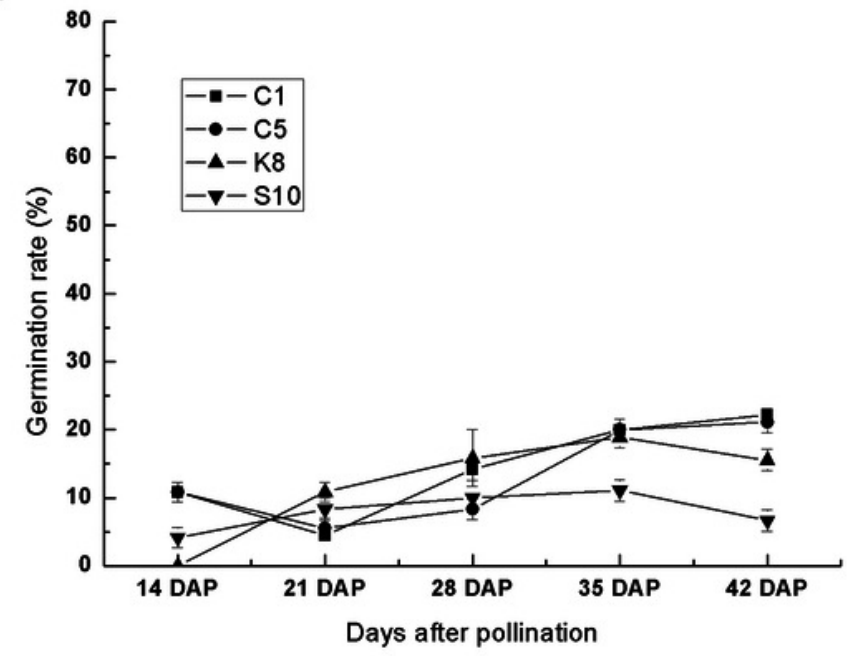




\section{Figure 4}

The seed germination patterns of 8 germplasms at different developmental stages during two consecutive years

(A) Seed germination at 14 DAP. (B) Seed germination at 28 DAP. (C) Seed germination at 42 DAP. Different letters indicate significant differences between the two years. Bars represent the mean \pm S.E. $(n=4)$ 


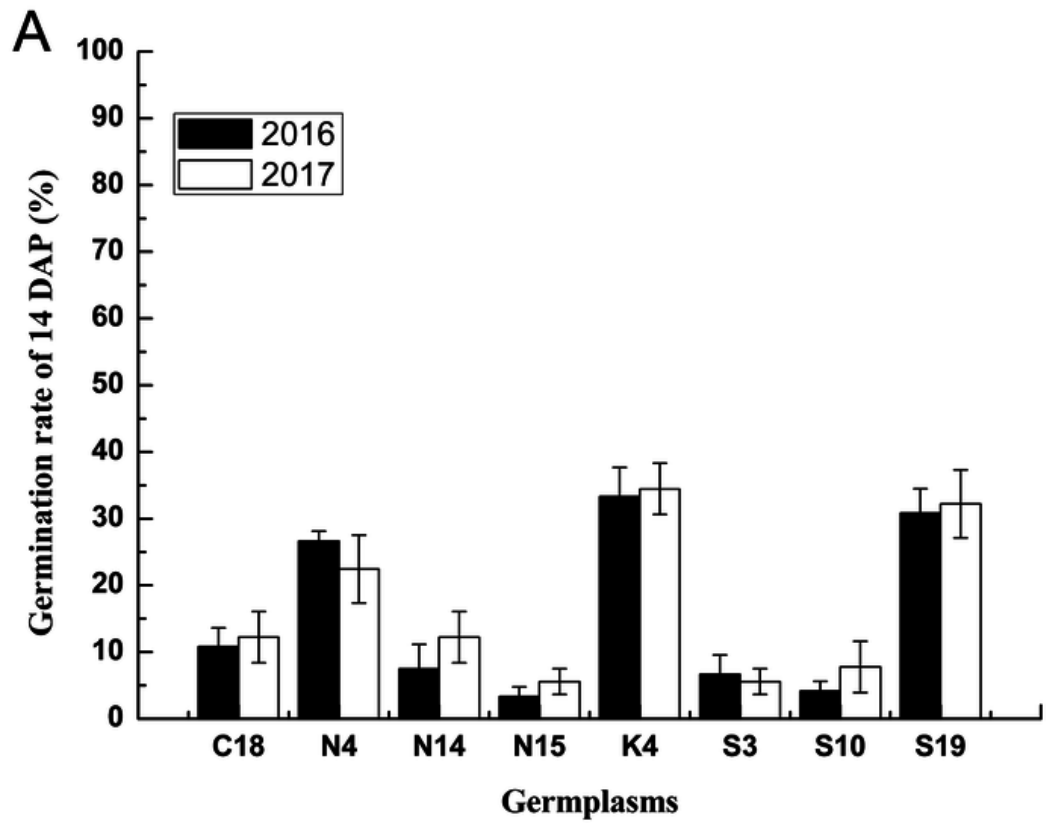

B
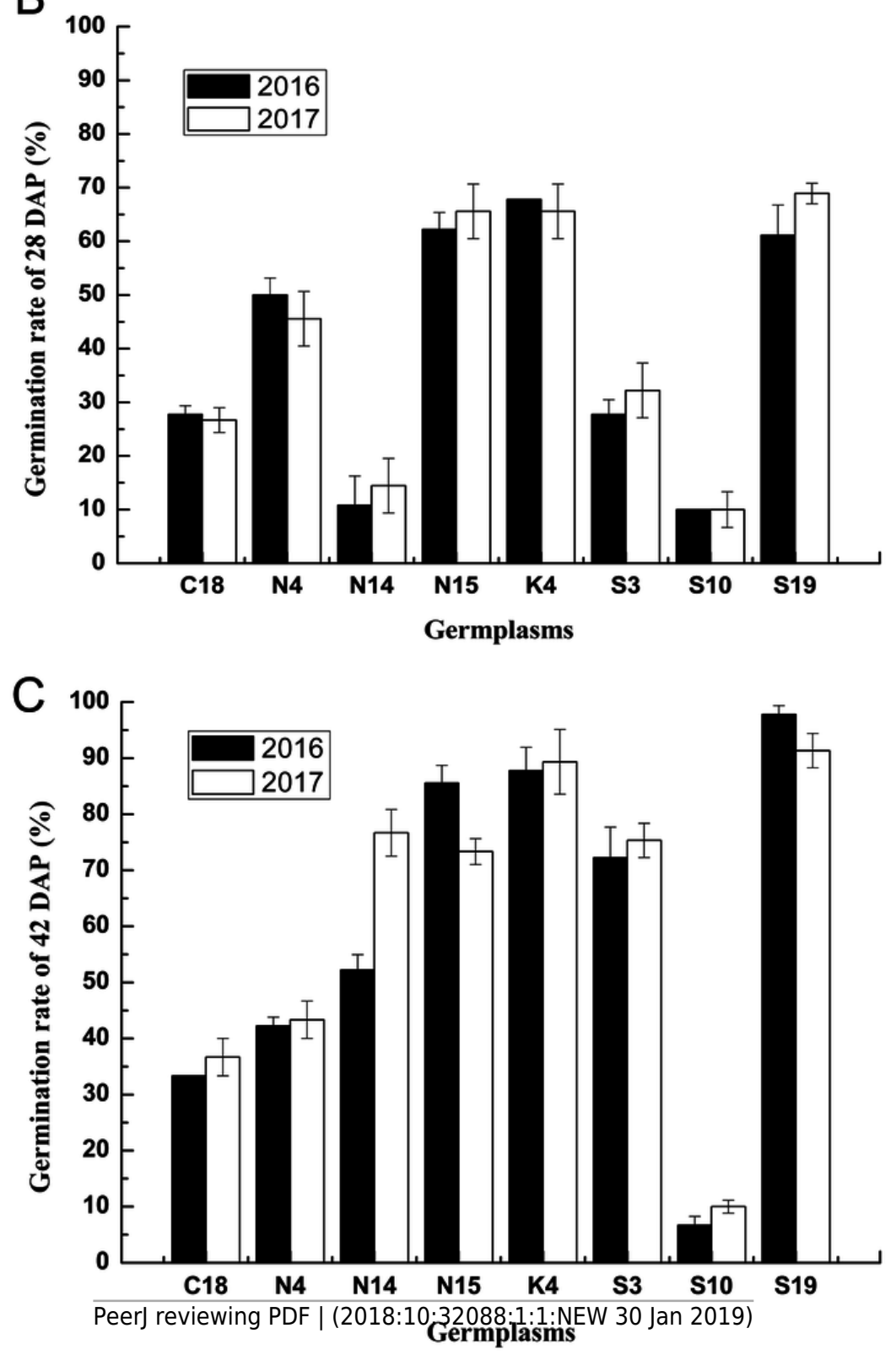
Figure 5

After-ripening effect on the seed germination rates of different sheepgrass germplasms after harvest

(A) Germination rate of the germplasms C5, N14, S3 continued to increase until 30 days after harvest and then tended to decrease. (B) The germination rate of germplasms S17, C18, and S19 began to increase at 15 days after harvest. (C) The germination rates of the germplasms Z37 and C19 continued to increase after harvest, and the germination rate of S10 did not decrease during the after-ripening process. (D) No increase in germination rate was observed in germplasm K4 after harvest. Bars represent the mean \pm S.E. $(n=4)$
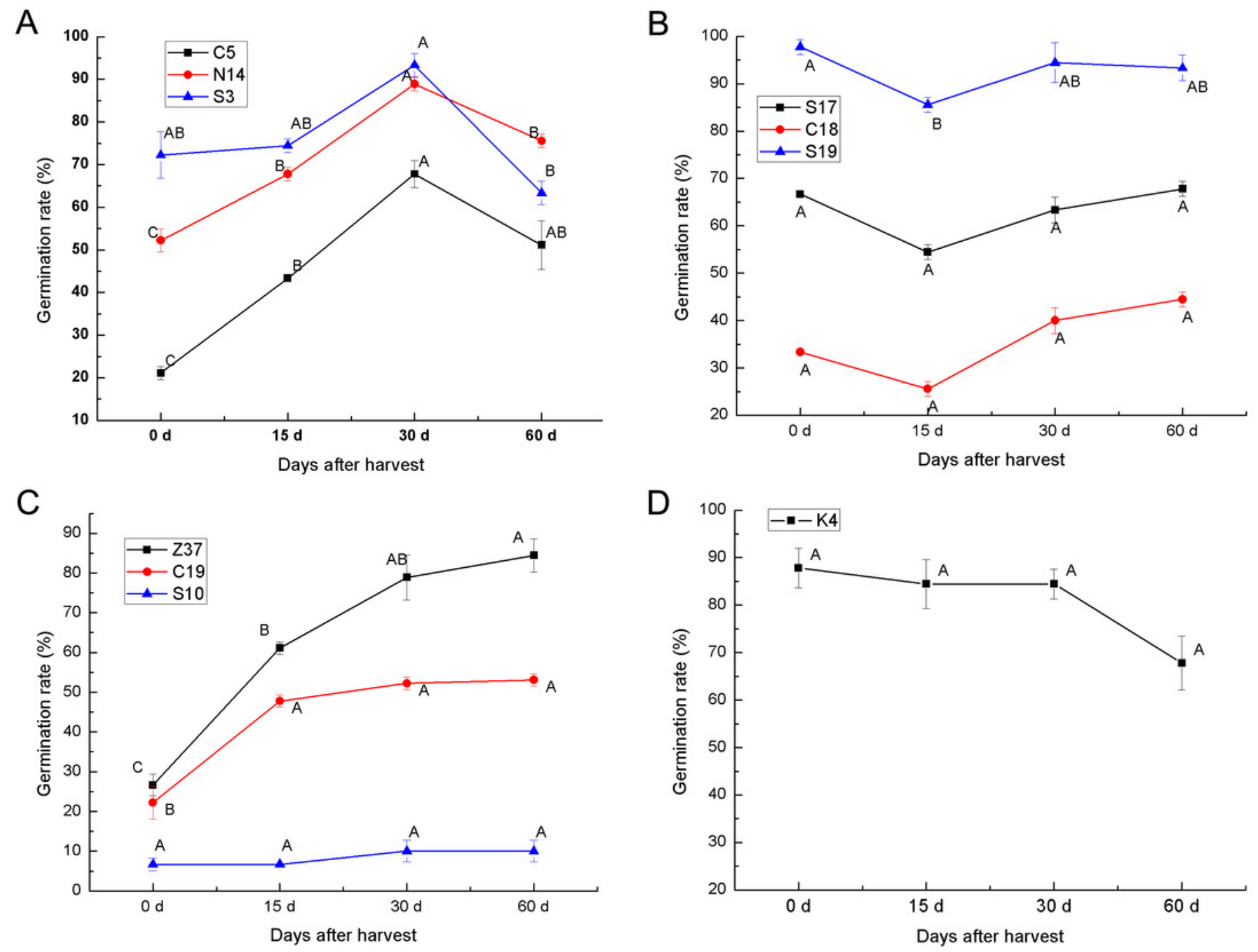


\section{Table $\mathbf{1}$ (on next page)}

Flowering time of experimental cultivars of sheepgrass

We classified the twenty cultivars of sheepgrass into three types according to the time of flowering. The six cultivars were considered as the early type which flowered on May 5 to May 10 in 2016; the flowering time of the mid type was May 11 to May 15, involving the seven germplasm s; Other seven cultivars which flowered on May 16 to May 20 were classified as the late type. 
1

\begin{tabular}{lcl}
\hline & Flowering time & Germplasms \\
\hline Early Type & May 5- May 10 & K8, C5, C1, Z37, C54, S17 \\
Mid Type & May 11 - May 15 & S10, S2, C19, S16, Q6, N4, N14 \\
Late Type & May 16 - May 20 & C18, S3, N2, N15, K4, S13, S19 \\
\hline
\end{tabular}

2

3 
Table 2 (on next page)

Two-factor analysis of variance of germplasm and developing stage 


\begin{tabular}{lccccc}
\hline Variance source & SS & df & MS & F & P-value \\
\hline Germplasms & 21573.19 & 19 & 1135.431 & 4.371028 & $1.94 \mathrm{E}-06$ \\
Developing stage & 24106.84 & 4 & 6026.71 & 23.2008 & $1.48 \mathrm{E}-12$ \\
Error & 19741.99 & 76 & 259.763 & & \\
Sum & 65422.02 & 99 & & & \\
\hline
\end{tabular}

1 df, Degree of freedom; MS, Mean Square; F, F-ratio.

2 Note: $P<0.05$ means significant difference, $P<0$. 01 means extremely remarkable difference, $\mathrm{E}$ is a 3 mathematic constant. 
Table 3(on next page)

Two-factor analysis of variance on the seed germination in different developing stages, 14 DAP, 28 DAP and 42 DAP, of the two consecutive years and different sheepgrass germplasms 
1

\begin{tabular}{llcccccc}
\hline & Variance Source & SS & df & MS & F & P & F crit \\
\hline \multirow{2}{*}{ 14 DAP } & Germplasm & 2047.276 & 7 & 292.468 & 75.70445 & $4.59 \mathrm{e}^{-6}$ & 3.787044 \\
& Year & 5.183211 & 1 & 5.183211 & 1.341658 & 0.284728 & 5.591448 \\
28 DAP & Germplasm & 7756.589 & 7 & 1108.084 & 136.0715 & $6.09 \mathrm{e}^{-7}$ & 3.787044 \\
& Year & 8.1225 & 1 & 8.1225 & 0.997434 & 0.351197 & 5.591448 \\
42 DAP & Germplasm & 11816.42 & 7 & 1688.06 & 28.85806 & 0.00012 & 3.787044 \\
& Year & 34.63976 & 1 & 34.63976 & 0.592181 & 0.466746 & 5.591448 \\
\hline
\end{tabular}

2 df, Degree of freedom; MS, Mean Square; F, F-ratio.

3 Note: $P<0.05$ means significant difference, $P<0$. 01 means extremely remarkable difference, e is a 4 mathematic constant.

5 


\section{Table 4(on next page)}

Two-factor analysis of variance of germplasm and after-ripening time 


\begin{tabular}{lrrrccc}
\hline \multicolumn{1}{c}{ Variance source } & SS & df & MS & F & P-value & F crit \\
\hline Germplasms & 22412.84 & 9 & 2490.316 & 18.22975 & $2.72 \mathrm{E}-09$ & 2.250131 \\
After-ripening time & 1909.136 & 3 & 636.3786 & 4.658455 & 0.009478 & 2.960351 \\
Error & 3688.395 & 27 & 136.6072 & & & \\
Sum & 28010.37 & 39 & & & & \\
\hline
\end{tabular}

1 df, Degree of freedom; MS, Mean Square; F, F-ratio.

2 Note: $P<0$. 05 means significant difference, $P<0$. 01 means extremely remarkable difference, e is a 3 mathematic constant. 